\title{
DELITOS RESTRICTIVOS DE LA LIBERTAD DE EXPRESIÓN Y SU INCONSTITUCIONALIDAD. ANÁLISIS DE TRES CASOS RESUELTOS POR LA SUPREMA CORTE DE JUSTICIA DE LA NACIÓN RESTRICTIVE CRIMES OF FREEDOM OF EXPRESSION AND ITS UNCONSTITUTIONALITY. ANALYSIS OF THREE CASES SOLVED BY THE NATIONAL SUPREME COURT OF JUSTICE
}

\section{Moisés Israel FLORES PACHECO*}

RESUMEN. En el presente artículo se analiza la existencia de tipos penales en el orden jurídico mexicano que restringen la libertad de expresión y que se encuadran en la categoría de restricciones indirectas, la cuales están prohibidas por la Constitución. Se afirma que estos delitos tienen un efecto inhibidor de la difusión de opiniones, ideas e información en México, por generar un tipo de autocensura al prohibir, perseguir y sancionar conductas relacionadas con la obtención y difusión de información, así como otras formas de expresión. Para demostrar esta tesis, en primer término se conceptualiza la libertad de expresión y su importancia destacando sus dimensiones: individual y social. Enseguida se hacen aproximaciones conceptuales de la censura, la censura previa y la autocensura como especies de restricciones a la libertad de expresión. Finalmente, se plantea de manera ejemplificativa la revisión de tres casos resueltos por la Suprema Corte de Justicia de la Nación de México, en los cuales se declaró la inconstitucionalidad de este tipo de delitos.

* Licenciado en derecho por la UNAM; Máster en derecho constitucional por la Universidad de Castilla-La Mancha;mifp11@hotmail.com.

Fecha de recepción: 24 de junio de 2019.

Fecha de dictamen: 28 de octubre de 2019. 
PALABRAS CLAVE. Libertad de expresión, censura, autocensura, delitos de difamación, injuria y calumnia, delito de perturbación al orden público, delito de "Halconeo".

ABSTRACT. This article analyzes the existence of definitions of crime in the Mexican legal system that restrict freedom of expression and that fall in the category of indirect restrictions, which are prohibited by the Constitution. It affirms that these definitions have an inhibiting effect of the diffusion of opinions, ideas and information in Mexico, for generating a type of self-censorship given that they prohibit, pursue and sanction conducts related to the obtention and spread of information, as well as other forms of expression. To demonstrate the thesis, firstly, the text conceptualizes freedom of expression and its importance, and highlights its dimensions: individual and social. Next, conceptual approaches to censorship, prior censorship, and self-censorship as restrictions on freedom of expression are made. Finally, by way of example, it reviews three analyzed cases by the Mexican Supreme Court in order to exemplify how these definitions were declared unconstitutional.

KEYWORDS. Freedom of expression, censorship, self-censorship, crimes of defamation, insult and slander, crime of disturbance to public order, crime of "Halconeo".

\section{LAS RESTRICCIONES INDIRECTAS A LA LIBERTAD DE EXPRESIÓN}

La libertad de expresión, en sus diferentes manifestaciones y contenidos, ha sido un tema de inquietud constante para los derechos humanos en México. En el informe "Situación de derechos humanos en México", aprobado por la Comisión Interamericana de Derechos Humanos el 31 de diciembre de 2015 , se señala una realidad preocupante sobre las agresiones más extremas hacia quienes hacen uso de la libertad de expresión, y que consisten en detenciones, secuestros, desapariciones, e incluso en asesinato de periodistas (CIDH, 2015: 17).

Sin embargo, este tipo de agresiones — que son las más trágicas e inadmisibles por su grado de afectación directo sobre la vida y la integridad personal_ no son las únicas a las que están sujetos quienes hacen uso de la libertad de expresión, sino que existe un conjunto más amplio de ac- 
ciones que se encuadran en otra categoría de vías o medios indirectos de restricción a dicha libertad. Este último tipo de agresiones tiene el mismo efecto que las primeras, pues se caracterizan por el efecto de inhibir el ejercicio de la libertad de expresión.

Estos medios o vías indirectos de restricción están previstos en la Constitución mexicana, donde se declaran prohibidos. Tal proscripción se consagra como una garantía de la libertad de difundir opiniones, información e ideas a través de cualquier medio, según se aprecia de la lectura del artículo 7o. constitucional. A partir de ello se puede inferir que existen dos tipos de restricciones a la libertad de expresión: las directas, que consistirían en un ataque inmediato a las personas para inhibir el ejercicio de este derecho, y que se caracterizan por ser más extremas al trasgredir claramente la libertad e integridad personales, y las indirectas, que se hacen valer a través de cualquier vía o medio, como pueden ser el abuso de controles oficiales de la información.

La Constitución no enuncia de forma exhaustiva y limitativa cuáles son los medios indirectos de restricción a la libertad de expresión, sino que deja abierta la lista, no en función de su forma, sino simplemente por su efecto: inhibir. En el primer párrafo del artículo 7o. constitucional se prescribe que:

Es inviolable la libertad de difundir opiniones, información e ideas, a través de cualquier medio. No se puede restringir este derecho por vías o medios indirectos, tales como el abuso de controles oficiales o particulares, de papel para periódicos, de frecuencias radioeléctricas o de enseres y aparatos usados en la difusión de información o por cualesquiera otros medios y tecnologías de la información y comunicación encaminados a impedir la transmisión y circulación de ideas y opiniones.

Esa descripción que hace la Constitución mexicana, de manera general y no limitada, permitiría calificar como una violación indirecta a la libertad de expresión, cualquier acto que impida su ejercicio, aun cuando pueda tratarse de una restricción legal. Debe pensarse de manera concreta en la existencia de normas penales que describan tipos por los que se sancione el ejercicio de esta libertad, frente a los cuales, por temor a las consecuencias, el individuo prefiere optar por la autocensura, pues antes que sufrir sanciones penales decide limitarse a sí mismo en aquello que dice.

Este tema no es exclusivo del ámbito nacional, sino que es posible encontrar precedentes importantes en el ámbito interamericano. Como 
Esta revista forma parte del acervo de la Biblioteca Jurídica Virtual del Instituto de Investigaciones Jurídicas de la UNAM

muestra está el Caso Usón Ramírez vs. Venezuela, donde se analizó el artículo 505 del Código Orgánico de Justicia Militar, el cual establecía una pena de tres a ocho años de prisión a quien de alguna forma injuriara, ofendiera o menospreciara a las Fuerzas Armadas Nacionales de aquel país, o a alguna de sus unidades. En ese caso, la Corte Interamericana de Derechos Humanos (Corte IDH) concluyó que la sanción penal de quien exprese 36 opiniones que puedan ofender o menospreciar a las instituciones resulta incompatible en materia de libertad de expresión, así como una restricción innecesaria en una sociedad democrática. ${ }^{1}$

Una vez apuntado lo anterior, el presente artículo tiene por objetivo plantear la existencia de algunos delitos que representan un obstáculo para la libertad de expresión protegida en la Constitución. En ese sentido, la cuestión que orienta este trabajo es indagar si ciertos delitos establecidos por el legislador pueden llegar a afectar o inhibir el ejercicio de esa libertad de manera indirecta e injustificada, y si por esa razón serían normas inconstitucionales. La tesis planteada es que tales delitos se pueden identificar en la categoría de restricciones indirectas a la libertad de expresión debido a que prohíben, persiguen y sancionan conductas relacionadas con la obtención y difusión de información, y así tienen por efecto inhibir la difusión de opiniones, ideas e información en México. Este efecto es generado no de modo directo, sino por vía indirecta, generando un tipo de autocensura y de ahí se sigue su invalidez.

El propósito central es reflexionar en torno a figuras delictivas que tienen un efecto inhibidor de esa libertad protegida por el orden jurídico mexicano. Para ello, en primer término se conceptualiza la libertad de expresión y su importancia destacando sus dimensiones: individual y social. Enseguida se hacen aproximaciones conceptuales de la censura, la censura previa y la autocensura como tipos de restricciones a la libertad de expresión. Finalmente, se plantean de manera ejemplificativa tres casos demostrativos de delitos que sancionan de manera indirecta el derecho a expresarse. Por último, se hace una reflexión general sobre el tema.

\section{ELEMENTOS PARA LA CONCEPTUALIZACión}

DE LA LIBERTAD DE EXPRESIÓN

La libertad de expresión es un derecho humano que tiene diversas facetas y múltiples manifestaciones; ello hace difícil definirlo de una manera comple-

1 Véase el Caso Usón Ramírez vs. Venezuela (2009: párrafos 55, 56, 57, 58 y 86). 
ta, en tanto toda definición es una limitación. En este apartado, más bien, se señalarán algunos elementos para su conceptualización.

Un buen comienzo puede ser, como hace Ernesto Villanueva, definir la expresión, la cual, de acuerdo con dicho autor, es la forma en como una persona manifiesta sus pensamientos a través de signos, en palabras o gestos, y que tiene por propósito comunicar algo (Villanueva, 1998: 27). Así, puede apreciarse que el objeto de la libertad de expresión es proteger la acción de comunicar.

Dos elementos más a destacar son: 1) el contenido material, el cual es amplio y abarca el discurso político, religioso, académico, científico, artístico, literario, comercial y cualquier otro, siempre y cuando no ataque a la moral, la vida privada o los derechos de terceros, provoque algún delito, o perturbe el orden público;22) los medios sobre los que ésta se puede ejercer; es decir, los vehículos de la comunicación que también están ampliamente protegidos constitucionalmente, dado que la norma fundamental expone, en su artículo 7o., que es inviolable la libertad de difundir opiniones, ideas o expresiones a través de cualquier medio.

Por otra parte, uno de los elementos importantes de esta libertad $-\mathrm{y}$ que constituye por sí mismo un derecho- es poder buscar y recibir informaciones de toda índole y por cualquier medio. Esto es: en la libertad de expresión se incluye una protección al derecho a la información. La libertad de información debe ser vista como un derecho que forma parte de la libertad de expresión. No se puede proteger la libertad de expresión sin proteger la libertad de buscar, obtener y difundir información, dado que son derechos interdependientes.

El derecho a la información también tiene la característica de la universalidad, la cual, como bien señala Escobar de la Serna, se manifiesta en una triple perspectiva: la universalidad geográfica, por la cual los mensajes pueden hoy en día atravesar las fronteras; la universalidad de medios, puesto que los mensajes se difunden por todos los medios de comunicación, y la universalidad subjetiva, en tanto se trata de un derecho de todos los individuos (Escobar, 2000: 87). Por tanto, la universalidad debe ser garantizada en estas tres perspectivas a fin de que la libertad de informar pueda hacerse efectiva como un derecho humano plenamente protegido por las normas constitucionales.

La libertad de expresión y la de información que le es ingénita encuentran protección en el orden jurídico nacional mediante la integración de dos normas constitucionales que consagran diversas garantías a

\footnotetext{
2 Estas limitantes se contemplan en el artículo 6o. constitucional.
} 
Esta revista forma parte del acervo de la Biblioteca Jurídica Virtual del Instituto de Investigaciones Jurídicas de la UNAM

su favor; a saber, los artículos 6o. y 7o. de la Constitución mexicana que señalan:

1) La manifestación de las ideas no será objeto de inquisición judicial o administrativa, sino en el caso de que se ataque la moral, los derechos de terceros, se provoque algún delito o perturbe el orden público.

2) El derecho a la información será salvaguardado por el Estado.

3) Toda persona tiene derecho a buscar, recibir y difundir información e ideas de toda índoles por cualquier medio de expresión.

4) No se puede vulnerar la libertad de escribir y publicar sobre cualquier materia.

5) Los límites a la libertad de escribir y publicar sobre cualquier materia serán el respeto a la vida privada, a la moral y a la paz pública.

6) Es inviolable la libertad de difundir opiniones, información o ideas a través de cualquier medio.

7) No se puede restringir este derecho por vías o medios indirectos.

8) Ninguna ley ni autoridad pueden establecer censura, ni pedir fianza a los autores o impresores o coartar la libertad de imprenta.

Debe mencionarse, además, que la libertad de expresión también está consagrada en diversos instrumentos internacionales; a saber: en el artículo 19 de la Declaración Universal de los Derechos Humanos; el artículo 19 del Pacto Internacional de Derechos Civiles y Políticos; el artículo 13 de la Convención Americana sobre Derechos Humanos; el artículo IV de la Declaración Americana de Derechos y Deberes del Hombre; el artículo 4o. de la Carta Democrática Interamericana, y en la Declaración de Principios sobre Libertad de Expresión. La suma de ese cúmulo de protecciones jurídico-normativas deja de manifiesto que la libertad de expresión —que abarca el acceso a la información - es un derecho humano relevante por ser indispensable para el respeto y la garantía de otros derechos y libertades que trascienden de la esfera individual para llegar a la esfera social.

Esta libertad es vital para las sociedades democráticas, ya que hay quienes incluso hacen del ejercicio de esta libertad su actividad cotidiana y su profesión, como es el caso de los periodistas. Los periodistas y aquellos que se dedican a la actividad periodística se sirven de la libertad de expresión para, a su vez, servir a la sociedad en un ciclo informativo que permite la difusión de información e ideas, y abre el debate y la crítica social. Por ello, la trascendencia de proteger la libertad de expresión ha 
adquirido el rango de derecho fundamental desde los inicios del constitucionalismo moderno.

Destacar este punto es clave para demostrar que una violación a la libertad de expresión provoca múltiples violaciones a otros derechos. Por ejemplo, la criminalización atenta contra la libertad e integridad personal y contra la seguridad jurídica y el debido proceso, pero estas afectaciones trascienden de la persona a quien se aplica la norma penal a la sociedad en general, que se ve frenada en el ciclo informativo por una censura en la expresión y difusión de la información.

La Primera Sala de la Suprema Corte de Justicia de la Nación (SCJN) en México ha adoptado la idea de que la expresión tiene una "doble faceta: por un lado, asegura a las personas espacios esenciales para el despliegue de su autonomía y, por otro, goza de una vertiente pública, colectiva o institucional que la convierte en pieza básica para el adecuado funcionamiento de la democracia representativa" (Tesis 1a. CCXV/2009).

Estas ideas encuentran previo arraigo en la Corte IDH, que ha manifestado que la libertad de expresión tiene dos vertientes - la individual y la social-, explicando que quienes están bajo la protección de la Convención Americana sobre Derechos Humanos "tienen no sólo el derecho y la libertad de expresar su propio pensamiento, sino también el derecho y la libertad de buscar, recibir y difundir informaciones e ideas de toda índole. Es por ello que la libertad de expresión tiene una dimensión individual y una dimensión social" (Caso Ricardo Canese vs. Paraguay, 2004: párrafo 77).

Respecto a la dimensión social, la Corte Interamericana ha dicho que "lleva implícita la función de mantener informada a la sociedad en general, e implica un deber de información como parte de la vida democrática de un Estado, por ser un medio para el intercambio de ideas e informaciones entre las personas; que comprende su derecho a tratar de comunicar a otras sus puntos de vista” (Caso Ricardo Canese vs. Paraguay, 2004: párrafo 79). El mismo tribunal declara que

...la dimensión individual de la libertad de expresión comprende el derecho a utilizar cualquier medio apropiado para difundir opiniones, ideas e información y hacerlo llegar al mayor número de destinatarios. En este sentido, la expresión y la difusión son indivisibles, de modo que una restricción de las posibilidades de divulgación representa directamente, y en la misma medida, un límite al derecho de expresarse libremente (Caso Norín Catrimán y otros Dirigentes, miembros y activista del Pueblo Indígena Mapuche vs. Chile, 2014: párrafo 372). 
Esta revista forma parte del acervo de la Biblioteca Jurídica Virtual del Instituto de Investigaciones Jurídicas de la UNAM

En los artículos 1o. y 2o. de la Declaración de Principios sobre Libertad de Expresión se señala que no hay personas ni sociedades libres sin libertad de expresión y de prensa, y que el ejercicio de ésta no es una concesión de las autoridades, sino que es un derecho inalienable del pueblo. Asimismo, sustenta la idea de que toda persona tiene el derecho a buscar y recibir información, expresar opiniones y divulgarlas libremente, y que nadie puede restringir o negar estos derechos.

Puede apreciarse la especial protección de la libertad de expresión, ya que ésta se extiende a la circulación de ideas, a la búsqueda y difusión de informaciones, pero también a otras acciones íntimamente relacionadas, como la posibilidad de indagar y cuestionar, de exponer y reaccionar, de coincidir y discrepar, de dialogar y confrontar, de publicar y transmitir informaciones (como se define en el preámbulo de la Declaración de Chapultepec), y que estas acciones constituyen una característica de una sociedad libre y democrática.

Los elementos hasta ahora expuestos permiten conceptualizar a la libertad de expresión como un derecho humano que goza de la protección constitucional e internacional, y que consiste en poder comunicar ideas, opiniones e informaciones de cualquier índole y por cualquier medio; por ende, abarca el derecho a la información, y que además tiene una doble vertiente: individual y social. Ello nos permite reconocer que su ejercicio es base y pilar del Estado democrático y de derecho.

\section{Censura, Censura previa y autocensura}

La censura, la censura previa y la autocensura son medios de restricción de la libertad de expresión, tomando en cuenta que el primero de ellos es válido, y los segundos pueden ser estimados inválidos en el orden nacional. El presente acápite es una aproximación conceptual para entender estos tipos de restricciones.

La Constitución mexicana refiere en el artículo 7o. que "Ninguna ley ni autoridad puede establecer la previa censura". De este texto se puede inferir que la acción constitucionalmente prohibida no es en sí misma la censura, sino la censura previa, la cual toma bajo el adjetivo "previa" una acepción diferente. El verbo "censurar", en términos comunes, significa formar juicio de una obra, o bien corregir o reprobar algo o a alguien.

En cambio, la censura previa, según la define el Diccionario de la lengua española de la Real Academia Española, es el "examen y aprobación que de ciertas obras hace un censor autorizado antes de hacerse públicas”. 
La censura previa implica, como expone Arjona Estévez, una determinación que tiene una autoridad legislativa, ejecutiva o judicial, para impedir la circulación de ideas o de información antes de llegar al espacio público, o bien exigiendo o condicionando su modificación para poder ser dados a conocer (Arjona, 2013: 961).

Por su parte, González Pérez afirma al respecto que

...el ejercicio de la libertad de expresión se garantiza con la prohibición de la censura, que implica que el Estado no puede someter las actividades expresivas o comunicativas de los particulares a la necesidad de solicitar un permiso a la autoridad, ... la prohibición de la censura no significa que la libertad de expresión sea un derecho absoluto, lo que no puede es sujetarse a medidas de control preventivo, solo puede someterse a responsabilidades ulteriores (González, 2014: 887).

René Avilés da cuenta, en un estudio, cómo, a pesar de que la Constitución ha consagrado estas prohibiciones de censura desde 1917, durante gran parte del siglo XX el gobierno mexicano empleó toda clase de prácticas para restringir la actividad periodística. El abuso de controles oficiales y una vigilancia de la actividad periodística desde la Secretaría de Gobernación permitió que el gobierno tuviera el control pleno de los medios de comunicación, y señala entre estas causas a la censura y a la autocensura:

El Estado Mexicano, ... ha logrado el control pleno de los medios, sin importar su respectiva naturaleza. Comenzó con la prensa escrita y luego, subsecuentemente, continuó con los nuevos medios conforme éstos fueron surgiendo. A ello han contribuido la "institucionalización" de la corrupción, la sujeción del periodismo al poder político, la censura y la propia autocensura (Avilés, 2007).

El Estado queda constitucionalmente impedido a la censura previa; no obstante, en ocasiones puede imponer una censura de manera indirecta generando vías que logran evitar que determinadas formas de expresión o información sean generadas. En estos casos, como señala De la Parra, "no se hace un reproche directo al mensaje que se pretende comunicar, pero sí se impide o se dificulta esa comunicación, a través de otras formas" (2015: 62). Es entonces que se crean medios para configurar la autocensura; es decir, la limitación que se impone la persona a sí misma para no sufrir alguna consecuencia por el ejercicio de expresarse. Así, puede pensarse que los tipos penales que restringen la libertad de expresión son en sí mismos una restricción indirecta, ya que su resultado es la autocensura. 
Esta revista forma parte del acervo de la Biblioteca Jurídica Virtual del Instituto de Investigaciones Jurídicas de la UNAM

Es ilustrativa, al respecto, la posición que tomó la Corte de Constitucionalidad de Guatemala, en el expediente 112-2005, sentencia del 1 o. de febrero de 2006, en la cual sostuvo que la expectativa de ser sancionado penalmente por expresar opiniones puede desalentar a un particular a expresarse; de manera que si bien la normativa penal no contempla una censura expresa, sí puede motivar a una autocensura del propio ciudadano en asuntos sobre los cuales, en un sistema democrático, se requiere de su expresión crítica para motivar el correspondiente escrutinio de la función pública (CIDH, 2012: 205).

Esta protección a la libertad de expresión se encuentra además incorporada por vía de tratados internacionales, pues el artículo 13, inciso 2, de la Convención Americana sobre Derechos Humanos, también prohíbe de manera expresa la censura previa y sólo se reconocen responsabilidades ulteriores. Resulta interesante, como hace notar Damián Loreti, que el sistema interamericano brinda una protección más amplía en comparación con el sistema europeo, ya que en éste — de acuerdo con el artículo 10 de la Convención para la Protección de Derechos Humanos y Libertades Fundamentales - se habilita a los Estados a sostener mecanismos de revisión y autorización previa de contenidos. Esa diferencia entre ambos sistemas ha propiciado que la Corte Interamericana genere una amplia jurisprudencia para prohibir este control previo de la libertad de expresión y de difundir información (Loreti y Lozano, 2014: 104).

De este modo, se concluye, por una parte, que la censura previa, entendida como una aprobación o permiso de la autoridad para expresarse de alguna determinada forma, está constitucional y convencionalmente prohibida en el orden jurídico mexicano, y por otra, que la autocensura, entendida como la decisión del individuo que se inhibe en el ejercicio de la libertad de expresión para evitar sufrir consecuencias legales, es resultado del uso de medios que encuadran en la categoría de medios indirectos de restricción a la libertad de expresión, también prohibidos por la Constitución mexicana, como se señaló en el acápite inicial.

Es por eso que este artículo sostiene que en ciertos casos las leyes penales pueden generar el fenómeno de la autocensura, y por tanto, que este tipo de leyes tratan de una restricción por vías o medios indirectos de la libertad de expresión, los cuales, como se ha explicado, están prohibidos en la Constitución mexicana. Es así que las leyes penales que generan autocensura son inconstitucionales, por encuadrar en la categoría de medios indirectos de restricción de la libertad de expresión. Revisar algunos de estos asuntos es la intención del presente artículo. 


\section{AnÁlisis de tipos penales Restrictivos \\ DE LA LIBERTAD DE EXPRESIÓN}

En el presente apartado se estudian tres delitos en el orden jurídico mexicano que han sido declarados por la SCJN como restricciones indirectas a la libertad de expresión y al derecho de acceso a la información. Lo anterior se refiere a los delitos de difamación, injurias o calumnias; después el delito de perturbación al orden público, y, finalmente, el delito de "halconeo".

Madrazo y Vela han sostenido, apoyados en el análisis de diversos casos, que la SCJN se ha movido progresivamente en materia de interpretación constitucional entre dos modelos de comprender la libertad de expresión. Estos modelos son el clásico y el democrático. El primero se caracteriza por concebir la libertad de expresión como un derecho de primera generación que se traduce en la obligación del Estado de no interferir: su valor es más individual y moral. En cambio, el segundo modelo se concibe como una condición necesaria para lograr el debate público de la democracia e informar a los ciudadanos, y en el que el Estado no debe ser visto como un censor, sino como un moderador que modula la expresión a fin de potenciar la expresión de otros; es decir, que el Estado no debe limitarse a respetar, sino que debe garantizar la libertad de expresión para que el debate público sea lo mas plural, incluyente y equitativo posible (Madrazo y Vela, 2013: 97-131).

Este segundo modelo es representado teóricamente por Owen M. Fiss, quien establece una distinción entre una teoría libertaria y una teoría democrática de la libertad de expresión, mediante un estudio de casos resueltos por la Corte Suprema de Estados Unidos en la forma de interpretar este derecho. En la primera teoría se protege el interés del individuo. En cambio, en la teoría democrática, el Estado debe actuar para ampliar la libertad de expresión, ya que es importante para la colectividad en el debate público (Fiss, 1999: 11-14).

Compartiendo esta visión evolutiva de la jurisprudencia de la SCJN es que se decidió hacer el examen de los siguientes casos, dado que en ellos se ha protegido la libertad de expresión contra leyes penales que la restringían de modo incompatible con la Constitución. Se observa que en estos asuntos existe una interpretación progresiva de la Corte sobre la importancia de la libertad de expresión, pues en ellos ha resaltado el papel de los derechos a expresarse y comunicar en la democracia, y concibe al Estado como un agente que además de respetar debe garantizar estos derechos. 
Esta revista forma parte del acervo de la Biblioteca Jurídica Virtual del Instituto de Investigaciones Jurídicas de la UNAM

En adición a lo anterior, estos casos han sido seleccionados para su análisis por ser considerados trascendentes en atención a tres criterios: a) han sido resueltos por la SCJN en su actuación como tribunal constitucional; $b$ ) por el procedimiento constitucional específico en que han sido resueltos, es decir, por tratarse de acciones de inconstitucionalidad, y c) porque el valor de sus consideraciones son de observancia obligatoria para los demás tribunales nacionales, de acuerdo con el artículo 43 de la Ley Reglamentaria del Artículo 105 Constitucional.

Aunado a lo anterior, existe la necesidad de divulgar cada vez más las resoluciones de la Suprema Corte como una doctrina constitucional con la cual se dan herramientas a los demás tribunales nacionales para la resolución de otros casos. En ese sentido, se comparte la opinión crítica de Pablo Coderch, quien hace notar que, tratándose de la libertad de expresión, un tribunal constitucional debe ocuparse más de la resolución de casos especiales donde se requiera la creación de jurisprudencia constitucional que facilite a la justicia ordinaria la resolución de casos más sencillos (Coderch, 2002: 21-23). En una línea similar, Ronald Dworkin ha señalado que "Los tribunales superiores deben trazar distinciones razonablemente rígidas que puedan servir de guía a los tribunales inferiores y otros ámbitos administrativos" (Dworkin, 2014: 455).

De ahí que se sostenga la pertinencia del análisis propuesto por dos razones importantes. La primera es conocer la interpretación que sobre la libertad de expresión ha hecho la Corte de México en su carácter de tribunal constitucional, destacando su importancia en la vida democrática, y por tanto, haciendo valer se prevalencia sobre las restricciones que se le han pretendido imponer. Esas interpretaciones se muestran como una evolución conceptual de este derecho humano que se acerca más a la teoría democrática que postulan autores como los arriba mencionados. En segundo lugar, porque derivado de esa interpretación, comienza a verse la generación de una doctrina constitucional que orienta a los tribunales nacionales en la forma en que deben resolver casos donde se encuentre implicada la protección de los derechos a expresarse o a informar. Por lo tanto, es importante hacer su estudio y divulgar las consideraciones más relevantes al respecto.

\section{Delitos de difamación, injuria y calumnia}

Estos delitos han tenido un amplio tratamiento en la doctrina jurídica de todos los países y han sido criticados principalmente porque las 
previsiones de estas conductas como delitos se prestaban a abusos por parte de funcionarios públicos que pretendían controlar la crítica al desempeño de sus funciones mediante la amenaza de cárcel. Por ejemplo, el concepto de difamación era tan amplio que permitía sancionar la difusión de información que aun siendo verdadera pudiera perjudicar la buena fama de algún servidor público (Coderch, 1987: 25 y 26).

De acuerdo con Loreti y Lozano, esta situación se ha modificado en la región de América Latina en los últimos veinte años, donde varios países han eliminado las sanciones penales asociadas a estas figuras. Entre estos países se puede mencionar a Argentina, Bolivia, Chile, Costa Rica, El Salvador, Guatemala, Honduras, Panamá, Paraguay, Perú y Uruguay (Loreti y Lozano, 2014: 109-114). Estos cambios han sido motivados en gran parte por los esfuerzos de los organismos del sistema interamericano de derechos humanos por hacer efectiva la prohibición de censura consagrada en la Convención Americana.

En México, la Comisión Nacional de los Derechos Humanos (CNDH) emitió la Recomendación General número 20, de 2013, donde se denuncia como una práctica que inhibe la libertad de prensa los casos en que servidores públicos o representantes de grupos fácticos de poder interponen denuncia penal por delitos de difamación, injuria o calumnia, cuando ven afectado su derecho al honor, inhibiéndose así la libertad de expresión (CNDH, 2013: 20).

El ombudsperson mexicano afirmó, en ese documento, que figuras delictivas como la difamación, la injuria o la calumnia se constituyen en un medio para establecer responsabilidades ulteriores por supuestos abusos a la libertad de expresión, y destaca el efecto inhibidor que la simple existencia de estas figuras penales puede tener en el debate político, en virtud de que a través de las mismas se restringe indirectamente la libertad de expresión, pues conllevan la amenaza de cárcel o multas para quienes presuntamente insultan u ofenden a un servidor público (CNDH, 2013: 20), por lo que el efecto que genera supera el estándar de la mínima restricción, derivado del miedo a perder la libertad por el hecho de criticar.

La Comisión Interamericana ha señalado, respecto a este tipo de leyes, que son un medio para silenciar ideas y opiniones, y que disuaden las críticas por el temor a las acciones judiciales, las sanciones penales o monetarias, por lo cual se suprime el debate esencial para el funcionamiento de un sistema democrático, restringiendo innecesariamente la libertad de expresión (Comisión IDH, 2012: 205).

En México, el 13 de abril de 2007, fueron derogadas las normas del ámbito federal que permitían enjuiciar criminalmente por injuria y calum- 
Esta revista forma parte del acervo de la Biblioteca Jurídica Virtual del Instituto de Investigaciones Jurídicas de la UNAM

nia, tras la publicación en el Diario Oficial de la Federación del decreto por el que se suprimieron del Código Penal Federal las figuras de injuria, difamación y calumnia. De manera específica, se derogó el artículo 361 del Código Penal que perseguía como delito la difamación y la calumnia contra el Congreso de la Unión, contra una de las cámaras, contra un tribunal o contra cualquier otro cuerpo colegiado o institución oficial.

Con la desaparición de estos delitos no se liberó de toda responsabilidad el ejercicio de la libertad de expresión, sino que únicamente se dejó el campo de la responsabilidad civil. En ese mismo decreto se puso la previsión de los artículos 1916 y 1916 bis del Código Civil Federal, por los cuales, aunque ya no son considerados delitos, sí tienen la calidad de hechos ilícitos las siguientes conductas:

I. El que comunique a una o más personas la imputación que se hace a otra persona física o moral, de un hecho cierto o falso, determinado o indeterminado, que pueda causarle deshonra, descrédito, perjuicio, o exponerlo al desprecio de alguien; II. El que impute a otro un hecho determinado y calificado como delito por la ley, si este hecho es falso, o es inocente la persona a quien se imputa; III. El que presente denuncias o querellas calumniosas, entendiéndose por tales aquellas en que su autor imputa un delito a persona determinada, sabiendo que ésta es inocente o que aquél no se ha cometido; y IV. Al que ofenda el honor, ataque la vida privada o la imagen propia de una persona (CCF, 2019).

En este sentido, la reforma representa un avance significativo siguiendo la tendencia marcada por distintos organismos internacionales y en la región latinoamericana, eliminando las sanciones penales que fijan responsabilidad por la difusión de una determinada información. El aspecto negativo de este tipo de normas eran los excesos que con su existencia cometieron las autoridades, ya que eran usadas como herramientas para evitar la crítica. De manera que se eliminaron a nivel federal normas legales que podían ser utilizadas para controlar o inhibir la actividad periodística o cualquier otra forma de expresión, y se dejaron sólo las responsabilidades del ámbito civil.

No obstante el ejemplo, esto no ha sido replicado por la totalidad de las entidades federativas, pues si bien en algunos códigos estatales el delito ha desaparecido —o en algunos otros, derogado-, aún existen leyes estatales penales en las cuales se sanciona penalmente la calumnia o la difamación. La situación de las 32 entidades federativas en esta materia se expone en la siguiente tabla: 


\begin{tabular}{|l|l|}
\hline \multicolumn{2}{|c|}{$\begin{array}{c}\text { Delitos de difamación, injurias y calumnias en la legislaciones } \\
\text { penales de las 32 entidades federativas de México }\end{array}$} \\
\hline $\begin{array}{l}\text { No lo contemplan: } \\
11 \text { entidades federativas. }\end{array}$ & $\begin{array}{l}\text { Aguascalientes, Baja California Sur, Chihuahua, } \\
\text { Coahuila, Durango, Estado de México, Guerrero, } \\
\text { Michoacán, San Luis Potosí, Tabasco, Tlaxcala. }\end{array}$ \\
\hline $\begin{array}{l}\text { Lo derogaron: } \\
13 \text { entidades federativas. }\end{array}$ & $\begin{array}{l}\text { Baja California, Chiapas, Distrito Federal, Guana- } \\
\text { juato, Jalisco, Morelos, Oaxaca, Puebla, Querétaro, } \\
\text { Quintana Roo, Tamaulipas, Sinaloa, Veracruz. }\end{array}$ \\
\hline $\begin{array}{l}\text { Existe y es vigente: } \\
7 \text { entidades federativas. }\end{array}$ & $\begin{array}{l}\text { Campeche, Colima, Hidalgo, Nuevo León, Sonora, } \\
\text { Yucatán, Zacatecas. }\end{array}$ \\
\hline $\begin{array}{l}\text { Declarado inconstitucional } \\
\text { por la SCJN: } \\
\text { una entidad federativa. }\end{array}$ & Nayarit. \\
\hline
\end{tabular}

FuENTE: elaboración propia con información verificada al 25 de junio de 2018.

El caso de Nayarit se trató de una resolución significativa de la SCJN en la Acción de Inconstitucionalidad 116/2015, iniciada por la CNDH en contra del artículo 355 del Código Penal de Nayarit, y resuelta el 29 de mayo de 2018, donde se declaró, por votación unánime, la invalidez del tipo penal de calumnias previsto en esa entidad. En ese caso se estimó que la norma penal no satisfacía el requisito de necesidad en una sociedad democrática, ya que no estaba adecuadamente orientada a satisfacer los intereses públicos, al interferir en el ejercicio del derecho de libre expresión de manera excesiva, afectando más a este derecho (y otros, como la libertad personal) que a aquellos bienes jurídicos que pretendía proteger.

No obstante, el caso de calumnia no es el único ejemplo de una ley penal que genera un efecto inhibidor de la libertad de expresión y que puede encontrarse en la experiencia mexicana. Existen otros casos significativos que son objeto de la presente reflexión.

\section{Delito de perturbación al orden público}

El 20 de septiembre de 2011 se publicó en la Gaceta Oficial del Estado de Veracruz una reforma al artículo 373 del Código Penal, donde se establecía que a quien, por cualquier medio, afirmara falsamente la existencia de aparatos explosivos u otros; de ataques con armas de fuego; o de sustancias químicas, biológicas o tóxicas que pudieran causar daño a la salud; ocasionando la perturbación del orden público, se le impondría prisión de 
Esta revista forma parte del acervo de la Biblioteca Jurídica Virtual del Instituto de Investigaciones Jurídicas de la UNAM

uno a cuatro años y multa de quinientos a mil días de salario, atendiendo a la alarma o perturbación del orden efectivamente producida (Diario de Debates, 2011:5).

En el Diario de Debates de la legislatura local que aprobó dicha norma se encuentran tres motivos para la creación de este delito: primero, tipificar una conducta que se extiende a la par de las "nuevas tecnologías de comunicación, en las que se propicia la rápida difusión de noticias o rumores y, con ello, el abuso en la propagación de falsedades que pueden causar alarma generalizada o pánico en una población"; segundo, que la falta de previsiones legislativas respecto de este fenómeno social distorsiona la comunicaciones con fines aviesos, y tercero, la necesidad de inhibir ese tipo de comportamientos antisociales que intentan ampararse en la libertad de expresión, libertad que se encuentra acotada por la Constitución federal en el caso de que se perturbe el orden público (Diario de Debates, 2011: 4-9).

El mismo Diario señala que la creación del delito surgió a partir de un caso concreto ocurrido el 25 de agosto de 2011, cuando en la zona conurbada Veracruz-Boca del Río se generó una psicosis por vía de redes sociales a partir de una falsa alarma sobre el ataque de grupos criminales a escuelas locales, lo que provocó que la gente, de manera desesperada, acudiera a las escuelas donde sus hijos estudiaban para recogerlos y ponerlos en un lugar seguro.

Contra la creación de este delito, el 17 de octubre de 2011, la CNDH promovió la Acción de Inconstitucionalidad 29/2011 ante la SCJN. La acción fue resuelta el 20 de junio de 2013 y se declaró la inconstitucionalidad de la norma por votación unánime, dado que el artículo 373 violaba el derecho a la libertad de expresión que reconoce la Constitución federal.

La Corte expresó que el legislador está facultado para limitar esta libertad, puesto que no existen derechos absolutos, pero también está constreñido dentro de su labor normativa a restringir de la menor manera posible la libertad de expresión y el derecho a la información. En el caso, la norma sancionaba las afirmaciones falsas sin precisar que sólo serían sancionables aquellas que se hicieran con intención dolosa de mentir y generar un daño. Por esa falta de precisión, se podría castigar penalmente a aquellas personas que difunden información falsa por equivocación y sin dolo. La Corte consideró que las afirmaciones erróneas están protegidas por libertad de expresión, pues son inevitables en el discurso.

Para el tribunal, la creación de un delito de esta naturaleza exigía la previsión de una intención dolosa en el agente del delito, ya que las afirmaciones falsas y no dolosas pueden provenir de una equivocación, como 
son las falsas alarmas, la cuales, con la creación de ese delito, podrían ser objeto de sanción. La misma imprevisión aplicaba para el supuesto que se conoce como "reporte fiel". Esto es: la norma penal no consideró que quien se limita a reproducir lo expresado por otro está exento de responsabilidad. Admitir la validez de este tipo penal significaba inhibir el libre flujo de información, ya que desde el medio de comunicación se obligaría a la censura, pues estarían obligados a verificar la veracidad de la información.

Bajo la tesis del reporte, la Corte estimó que las condiciones operativas de la norma impugnada generarían que se sancionara penalmente al que reproduce exactamente lo expresado por su fuente, a pesar de que en dicha reproducción no exista dolo (SCJN, 2013: 45). De ello se aprecia que el tipo penal no hacía diferenciación en la forma en como se difundía la falsa alarma: si era intencional o por equivocación. En consecuencia, resultaba extremadamente restrictivo porque sancionaba toda difusión de información falsa, sin tener en cuenta el error o el reporte fiel.

Más importante aún es el razonamiento de la Corte por el cual se señala que el delito, al no distinguir los medios de comunicación que sean vehículos de esa información, genera que la problemática se incremente con el desarrollo y creciente uso de Internet. De ese modo, la norma penal abarcaba a las redes sociales (blogs, Twitter, Facebook, Instagram, etcétera) y, por lo tanto, se constituían en espacios susceptibles de ser sancionados penalmente.

Se trata de una interpretación progresiva que deriva del artículo 7o. constitucional, en la cual se reafirma que es inviolable la libertad de difundir opiniones, ideas, expresiones "a través de cualquier medio", incluso en redes sociales. Hay interpretación jurisprudencial por parte de la SCJN respecto a la libertad de imprenta — entendida como parte de la libertad de expresión—, donde en esencia señala que atendiendo al dinamismo de las formas de comunicación actuales y al empleo de las nuevas tecnologías, debe entenderse a la libertad de imprenta en un sentido amplio y de carácter funcional, adscribiéndose no sólo al papel, sino incluso a los medios electrónico que "puedan hacerse del conocimiento del público en general, así como a las diversas formas audiovisuales — como lo es el cine y videoa través de las cuales puede desarrollarse la función que se pretende con la libertad de imprenta" (Tesis 1a. CCIX/2012).

Por eso, la SCJN consideró que penar una conducta como las falsas alarmas generaría un efecto inhibitorio muy grave, en el que personas bien intencionadas puedan sentirse cohibidas o amedrentadas para expresar alertas. Con ese desaliento y obstrucción se afecta no sólo la libertad de expresión, sino también el derecho a la información, que entre mayor re- 
Esta revista forma parte del acervo de la Biblioteca Jurídica Virtual del Instituto de Investigaciones Jurídicas de la UNAM

vista interés público, como es la alarma de un posible peligro, mayor es el grado de protección que debe gozar (SCJN, 2013: 45 y 46).

La existencia del artículo impugnado propiciaba por sí mismo el silencio de los gobernados respecto a situaciones que pueden llegar a alterar el orden público, perjudicando el flujo de información que debe existir en una sociedad democrática, por lo que tal precepto violaba el derecho de difundir información plasmado en el artículo 7o. constitucional, y de ahí se seguía su invalidez.

\section{Delito de "halconeo"}

El 10 de abril de 2013, la CNDH promovió la Acción de Inconstitucionalidad 11/2013 en contra del artículo 398 bis del Código Penal para el Estado de Chiapas (CPEC). Esta norma pretendía sancionar una actividad que se identifica de manera coloquial como "halconeo", entendido como el espionaje de las actividades de las fuerzas de seguridad pública para alertar a los grupos criminales. La función de un "halcón" (vigilante o informante) consiste en vigilar las actividades de personas o instituciones que amenacen la estabilidad de la organización criminal a la cual pertenece.

La CNDH planteó que el artículo 398 bis del Código Penal para el Estado de Chiapas era violatorio del derecho de acceso a la información por una deficiente tipificación del delito que afectaba a formas válidas de búsqueda de información y de expresión. La norma imponía una pena "de dos a quince años de prisión y multa de doscientos a cuatrocientos días de salario mínimo a quien realizara actos tendientes para obtener información de los cuerpos de seguridad pública, de persecución o sanción del delito o la ejecución de penas, sobre su ubicación, actividades, operativos o sus labores, en general" (CPEE, 2019). Nótese que la acción penada era obtener información y no la acción de entregarla a organizaciones criminales.

La Suprema Corte declaró la invalidez de ese artículo bajo el argumento central de que la acción perseguida penalmente se encontraba dentro del campo válido del ejercicio constitucional de la libertad de expresión. Es decir, que realizar actos tendentes para obtener información no podía ser una conducta constitutiva de delito, ya que esta actividad se relaciona con el derecho a la información, que por sí mismo no generaría un perjuicio social.

Aunque la norma perseguía una finalidad válida — como era proteger las actividades de seguridad pública de la delincuencia organizada- no 
satisfacía el requisito de necesidad, ya que la descripción típica era amplia (y por tanto deficiente), al abarcar un sinnúmero de conductas amparadas por el derecho de acceso a la información; es decir, que realizar actos tendentes para obtener información es una conducta que por sí misma no daña o pone en riesgo el bien jurídico tutelado.

El delito adolecía de las precisiones necesarias, ya que no se estableció la finalidad de que la información buscada debía investigarse para causar un daño en perjuicio de la seguridad pública. Dicho en otras palabras, la legislación no precisó que además de la obtención de información, debía haber la intención del sujeto activo del delito de darle un uso ilegal; tampoco expresó ningún otro elemento que permitiera identificar a la conducta como un abuso con fines criminales del derecho de acceso a la información, diferenciable de un ejercicio legítimo.

El tribunal estimó que validar la existencia de un delito así dificultaría el ejercicio del derecho de acceso a la información en tanto se trata de una medida demasiado amplia y excesiva que interfería con el ejercicio legítimo de tal libertad, porque se podrían incluir numerosos supuestos del ejercicio legítimo del derecho de acceso a la información, incluso tales como la formulación de solicitudes formales de información a las instituciones de seguridad pública (SCJN, 2014: 34).

La Corte específicamente señaló que la norma tenía un impacto desproporcional sobre un sector específico de la población: el gremio periodístico, porque al criminalizar la búsqueda de toda información relativa a la seguridad pública y a la procuración de justicia, es claro que uno de los sujetos destinatarios de la norma podrían ser los periodistas, quienes tienen como función social la de buscar información sobre temas de interés público a fin de ponerla en la mesa de debate, por lo que este delito terminaba teniendo un efecto inhibidor de la tarea periodística y el efecto de hacer ilícita la profesión en ese ámbito específico (SCJN, 2014: 35). En consecuencia, la acción se resolvió por unanimidad de votos en el sentido de declarar la invalidez del artículo 398 bis del Código Penal para el Estado de Chiapas.

Este mismo criterio se reiteró, el 6 de julio de 2015, por el Pleno de la Suprema Corte en la Acción de Inconstitucionalidad 9/2014, donde se invalidó el artículo 133 quinquies del Código Penal de Michoacán, que sancionaba con prisión de 4 a 12 años y multa de 100 a mil días de salario mínimo a quien obtuviera y proporcionara información sobre las actividades y operativos de las fuerzas armadas y cuerpos de seguridad, y en esencia reiteró los mismos argumentos de la acción de inconstitucionalidad anteriormente narrada. Es decir, que criminalizar la búsqueda de toda información relativa 
Esta revista forma parte del acervo de la Biblioteca Jurídica Virtual del Instituto de Investigaciones Jurídicas de la UNAM

a la seguridad pública y a la procuración de justicia termina por tener un efecto inhibidor de la libertad de buscar información y de la terea periodística si no se especificaba la finalidad dolosa de hacer mal uso de la información para beneficiar a organizaciones criminales.

\section{ReFLEXIÓN FINAL}

En México existen experiencias de creación de delitos que se constituyen en límites para el ejercicio de la libertad de expresión y de información, como son los casos analizados. Estas restricciones encuadran en la categoría de restricciones indirectas, las cuales están prohibidas en el artículo 7o. de la Constitución mexicana.

Las restricciones indirecticas a libertad de expresión no están definidas en su forma, sino por su efecto; es decir, que aunque no se puedan precisar cuáles y cuántas son, se pueden determinar a partir de sus resultados: la inhibición de la libertad de expresión, por ejemplo, mediante la autocensura.

La autocensura existe cuando se genera un temor a las consecuencias que implicaría determinada manifestación de opiniones, ideas o información, y el individuo prefiere optar por no expresarse, pues antes que sufrir las sanciones respectivas, elige limitarse a sí mismo en el ejercicio de su libertad de expresión.

Los tipos penales de los que se ha hecho examen fueron declarados inconstitucionales por sancionar conductas comunicativas que eran válidas, y, por tanto, eran restricciones a los derechos de expresión y de acceso a la información, que además tenían por resultado la autocensura.

Estos delitos, aunque no persiguen directamente el contenido directo de un mensaje o de una comunicación, sí dificultan el entorno, el medio, o la forma en que se realiza ese mensaje, imponiendo responsabilidades ulteriores que son desproporcionados o sobre inclusivas y afectan derechos fundamentales de primer orden, como es la libertad personal. Así, generan un efecto inhibidor, pues la ejemplaridad de la pena impide que otras personas se expresen por no ser sancionadas penalmente.

Las responsabilidades para el ejercicio de la libertad de expresión no deben ser desproporcionadas y no deben preferirse las penales como primera opción. Una sanción penal por expresar opiniones o por difundir información inhibe el ejercicio de la libertad de expresión, de manera que, si bien no es una censura previa, sí genera autocensura de la persona en asuntos de orden público y de interés para la vida de una sociedad democrática. 
Con la criminalización inadecuada o indebida de ciertas formas de la libertad de expresión se obstaculiza el ciclo informativo de una sociedad democrática, y en ocasiones se afecta específicamente a quienes hacen de la libertad de expresión su actividad cotidiana, como es el caso de quienes se dedican a la actividad periodística.

En las resoluciones analizadas, la Suprema Corte ha destacado dos dimensiones de la libertad de expresión: la individual y social. El tribunal señaló que con los tres tipos penales se restringiría no sólo el derecho de las personas en su aspecto individual, sino que se afectaba a la sociedad en general, pues se le privaba de la divulgación de información que podría ser de interés público, obstruyendo la posibilidad de buscar, recibir y difundir información relacionada con actividades públicas. Por lo tanto, puede verse en estas interpretaciones la consolidación de una doctrina constitucional que se acerca más a una teoría democrática de la libertad de expresión.

\section{Fuentes consultadas}

Arjona Estévez, Juan Carlos, 2013, "Prohibición de la censura previa: retos del siglo XXI", en Mac-Gregor Poisot, Eduardo Ferrer (coord.), Derechos humanos en la Constitución: comentarios de jurisprudencia constitucional e interamericana I, México, Suprema Corte de Justicia de la Nación, t. I.

AviLés, René, 2007, "La censura al periodismo en México: revisión histórica y perspectivas", Razón y Palabra, vol. 12, núm. 59, octubre-noviembre, disponible en: http://www.redalyc.org/articulo.oa?id=199520703007.

Coderch, Pablo Salvador, 2002, Libertad de expresión y conflicto institucional, España, Civitas.

Coderch, Pablo Salvador (coord.), 1987, ¿Qué es difamar? Libelo contra la Ley de Libelo, España, Civitas.

Dworkin, Ronald, 2014, Justicia para erizos, México, Fondo de Cultura Económica.

Escobar de la Serna, Luis, 2000, Principios del derecho de la información, España, Dykinson.

Fiss, Owen M., 1999, La ironía de la libertad de expresión, España, Gedisa. GonzÁlez Pérez, Luis Raúl, 2014, "Libertad de expresión”, en Diccionario de derecho procesal constitucional y convencional, México, UNAM, Instituto de Investigaciones Jurídicas. 
Esta revista forma parte del acervo de la Biblioteca Jurídica Virtual del Instituto de Investigaciones Jurídicas de la UNAM

LoReti, Damián y Lozano, Luis, 2014, El derecho a comunicar. Los conflictos en torno a la libertad de expresión en las sociedades contemporáneas, Argentina, Siglo Veintiuno Editores.

Madrazo Lajous, Alejandro y Vela Barba, Estafanía, 2013, "Repensando la libertad de expresión”, en González Pérez, Luis Raúl (coord.), Libertad de expresión y responsabilidad social: estudios en homenaje al doctor Jorge Carpizo, México, Oxford University Press.

Parra Trujillo, Eduardo de la, 2015, Libertad de expresión y acceso a la información, México, Comisión Nacional de los Derechos Humanos.

Villanueva Villanueva, Ernesto, 1998, Régimen jurídico de las libertades de expresión e información en México, México, UNAM, Instituto de Investigaciones Jurídicas.

\section{Informes y recomendaciones}

Comisión Interamericana de Derechos Humanos, 2015, Informe situación de los derechos humanos en México, 31 de diciembre, disponible en: http://www.oas.org/es/cidh/informes/pdfs/Mexico2016-es.pdf.

Comisión Interamericana de Derechos Humanos, 2012, Informe anual de la Comisión Interamericana de Derechos Humanos 2012, vol. II.

Comisión Nacional de los Derechos Humanos, 2013, Recomendación General número 20, 15 de agosto, disponible en: https://www.cndh.org. $m x /$ sites/default/files/doc/Recomendaciones/Generales/RecGral_020.pdf.

2. Diarios legislativos

"Diario de Debates del Cuarto Periodo de Sesiones Extraordinarias Primer Año de Ejercicio Constitucional Septiembre 2011 ”, año 1, vol. VIII, t. 1, septiembre de 2011, disponible en: https://www.legisver.gob.mx/diariode debates/diariodedebatesLXII/4o_Extraordinario_Septiembre_2011.pdf.

3. Corte Interamericana de Derechos Humanos

Caso Usón Ramírez vs. Venezuela, 2009, disponible en: http://www.corteidh. or.cr/docs/casos/articulos/seriec_207_esp.pdf. 
Caso Ricardo Canese vs. Paraguay, 2004, disponible en: http://www.corteidh. or.cr/docs/casos/articulos/seriec_111_esp.pdf.

Caso Norín Catrimán y otros Dirigentes, miembros y activista del Pueblo Indígena Mapuche vs. Chile, 2014, disponible en: http://www.corteidh.or.cr/ docs/casos/articulos/seriec_279_esp.pdf.

Declaración de Principios sobre Libertad de Expresión, disponible en: https:// www.cidh.oas.org/basicos/declaracion.htm.

4. Jurisprudencia

Tesis 1a. CCXV/2009, Semanario Judicial de la Federación y su Gaceta, Novena Época, t. XXX, diciembre de 2009.

Tesis 1a. CCIX/2012 (10a.), Semanario Judicial de la Federación y su Gaceta, Décima Época, t. 1, septiembre de 2012.

\section{Sentencias}

Suprema Corte de Justicia de la Nación, 2014, Sentencia de la Acción de Inconstitucionalidad 11/2013, 7 de julio, disponible en: https://www.cndh. org.mx/sites/default/files/doc/Acciones/Acc_Inc_2013_11_Demanda.pdf.

Suprema Corte de Justicia de la Nación, 2013, Sentencia de la Acción de Inconstitucionalidad 29/2011, 20 de junio, disponible en: https://www.cndh. org.mx/sites/default/files/doc/Acciones/Acc_Inc_2011_29_Demanda.pdf. 